\title{
Performance of the WHOQOL-BREF among Norwegian substance use disorder patients
}

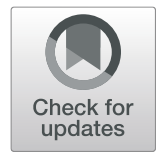

Ashley Elizabeth Muller ${ }^{1,2^{*}}$ (D), Svetlana Skurtveit ${ }^{1,3}$ and Thomas Clausen ${ }^{1}$

\begin{abstract}
Background: Quality of life (QoL) is an established outcome measure of substance use disorder treatment. The WHOQOL-BREF is the gold standard tool, but its appropriateness for particularly vulnerable patient populations must be further explored. This article examines the scaling qualities of the WHOQOL-BREF in a Norwegian substance use disorder population, and explores relationships with social and health variables.

Methods: 107 participants in a larger national treatment study provided data during structured interviews. Item responses, responsiveness, and domain scaling qualities are reported. General linear models identified correlates of impaired QoL.

Results: Three out of four domains exhibited acceptable scaling qualities, while the social relationships domain had low internal validity. 59\% of the variance in physical health QoL was explained in our model by the negative main or interaction effects of depression, unemployment, social isolation, smoking, residential treatment, and weight dissatisfaction. 52\% of the variance in psychological health QoL was explained by depression and being single. Depression also had significant main effects in social relationships QoL $\left(R^{2}=.27\right)$ and environment QoL $\left(R^{2}=.39\right)$, and social isolation and exercise had further interaction effects in environment QoL.

Conclusions: After one year in treatment, the impact of low social contact in reducing QoL, rather than specific substance use patterns, was striking. The social relationships domain is the shortest in the WHOQOL-BREF, yet social variables were important in other areas of QoL. Social support could benefit from more attention in treatment, as a lack of social support seems to be a strong risk factor for poor QoL in various domains. The WHOQOL-BREF exhibits otherwise satisfactory measurement characteristics and is an appropriate tool among this population.
\end{abstract}

Keywords: Quality of life, Substance use disorder, Psychometrics, Social isolation

\section{Background}

Reducing morbidity and improving the quality of life years spent with or in recovery from a substance use disorder (SUD) is as key to treatment as reducing mortality. In the management of chronic diseases, in which the negative effects of a disease are often reoccurring and long-lasting, treatment cannot be evaluated by a cure, but by sustained improvements in self-assessed functioning and well-being. The multidimensional measure of patient-reported outcomes such as quality of life (QoL) are important outcomes of the treatment of chronic

\footnotetext{
* Correspondence: ashley.muller@medisin.uio.no

'Norwegian Centre for Addiction Research, Institute of Clinical Medicine, University of Oslo, Pb 1039 Blindern, 0315 Oslo, Norway

${ }^{2}$ Division of Health Services, Norwegian Institute of Public Health, Pb 4044 Nydalen, 0403 Oslo, Norway

Full list of author information is available at the end of the article
}

diseases such as SUDs, as it captures the repercussive impacts of disease in many areas of life that may not be identifiable through normal clinical practice $[1,2]$. QoL is of further importance in SUD treatment because improving QoL may itself support treatment retention and abstinence after leaving treatment [3-5].

Reduced substance use is often assumed to automatically improve QoL. However, mixed evidence for this hypothesis among various SUD groups exists [6-9]. People may even instigate SUD treatment less to reduce their substance use than to improve their QoL in general $[4,10]$. Qualitative research has shown people with SUDs consider social factors such as enough relationships and contact, a supportive network, and social inclusion as necessary components to good QoL [11-13]. Indeed, these social settings may influence the development and

(c) The Author(s). 2019 Open Access This article is distributed under the terms of the Creative Commons Attribution 4.0 International License (http://creativecommons.org/licenses/by/4.0/), which permits unrestricted use, distribution, and 
trajectory of SUDs in general to a far greater extent than other chronic diseases, as substance use in a person's network impacts their own access to both substances and, later, to treatment [14-16].

Among non-SUD populations, several social determinants have been identified: Pinquart and Sorensen's [17] meta-analysis found that the quality of social relationships among the elderly was the second most important factor in their QoL, following independence. In a cross-sectional study of people with severe mental illness, higher QoL correlated to greater social support, lower internalized and societal stigma, and lower symptom distress [18], and in longitudinal studies of people with various mental illnesses, improvements in social integration along with symptom reductions have predicted QoL improvements over time [19-21]. Sociodemographic factors, age, and gender have not been consistent predictors in these studies.

Overall QoL was reported in the aforementioned studies through single or aggregate scores [17-19, 21]. Instruments can also measure QoL multidimensionally, in which separate domains of respondents' lives are queried and represented through separate domain scores. The gold standard in generic quality of life instruments, the World Health Organization's brief quality of life tool (WHOQOL-BREF), measures four domains of QoL: physical health, psychological health, social relationships, and environment QoL. Strong psychometric properties have been reported internationally [22] as well as among the general populations of Nordic countries [23-25]. Normative values for this generic instrument allow for the comparison between healthy and clinical groups, such as those with SUD, and to this end, the WHOQOL-BREF has also been validated among opioid maintenance treatment patients [26-28], a substance-using veteran population [29], and most recently among an exclusively alcohol-abusing sample [30].

Two reviews have concluded that most QoL instruments administered to people with SUD under-prioritize social domains in favour of health domains, and most research on QoL determinants continues to focus on substance use and mental health $[8,31]$. Two diseasespecific QoL tools - the Injecting Drug Users Quality of Life Scale [32] and the Opioid Substitution Treatment Quality of Life scale [13] - both include a broader focus on social domains, but disease-specific QoL tools cannot provide QoL scores that can be compared to other populations; a recent review discusses further merits of generic measures among opioid users [33].

The WHOQOL-BREF may be a preferable generic instrument among SUD populations, given that one of its strengths is the inclusion of a social QoL domain. QoL instruments such as the WHOQOL-BREF, if they are to allow for the subjective evaluation of the effects of SUD and treatment, must also be feasible and perceived as relevant to respondents. The WHOQOL-BREF has seldom been reported for Norwegian substance users, with a small pilot study being one exception [34]. We wished to explore the acceptability of the WHOQOL-BREF to SUD patients in Norway. We analysed the WHOQOL-BREF's item responses, responsiveness, scaling qualities, and explored the relationships of various health, substance, and social variables to each domain.

\section{Methods}

\section{Participants and procedure}

This paper analyses a subsample of a larger study, the Norwegian Cohort of Patients in Opioid Maintenance Treatment and other Drug Treatment study (NorComt), procedures for which have been previously described [35]. Briefly, NorComt consecutively enrolled 548 adults entering SUD treatment (either opioid maintenance treatment [OMT] or medication-free residential treatment) in 21 facilities between 2012 and 2015, with no exclusion criteria. They answered a battery of psychological and substance use questionnaires during structured interviews first when they entered treatment (baseline), by facility staff who had been trained by the research team. One year later (follow-up), the research team administered the same structured interviews to participants. There were again no inclusion criteria, and the interviews were conducted at locations chosen by participants. Sixty-two percent $(N=341)$ of the original sample at baseline was followed up with, and those lost to follow-up did not differ in terms of most baseline demographics or substance use indicators [36].

Ethical approval was granted by the Norwegian Regional Ethics Comittees (ref: 2012/1131/REK) to administer the WHOQOL-BREF to the first 100 participants consecutively interviewed at follow-up in order to assess a different instrument [37]. One hundred and seven participants ultimately answered the WHOQOL-BREF and were included in this analysis. Written informed consent was obtained from all patients before participation.

\section{Measures}

The structured interview questionnaire was built off of the national Patient Registry Questionnaire, containing demographic variables reported by all hospitals and private contract specialists [38]. Numerous validated measures were added and are described below.

\section{WHOQOL-BREF}

The World Health Organization's WHOQOL-BREF has been validated in dozens of countries and languages, and among healthy and clinical populations [22], and its appropriateness as a generic, multidimensional tool for the SUD population has been highlighted [1]. The WHOQOL-BREF produces four domain scores from 24 items: a 3-item 
"social relationships" domain of QoL, 7-item "physical health" domain, 6-item "psychological health" domain, and 8-item "environment domain". Two additional items measure overall QoL and overall health. The WHOQOL-BREF uses a five-point Likert scale with answers from "very dissatisfied" to "very satisfied", "not at all" to "an extreme amount", and "never" to "always". Transformed domain scores resulted in a 0-100 scale in which higher scores indicate higher QoL [39].

\section{Demographic, substance, and health measures}

Demographic variables included civil status ("single" or "married/partnered"), unemployment, and educational attainment of primary school or less. Substance use was measured by the substance profile from the EuropASI, which collects individuals' four most commonly used illicit substances/unprescribed medications in the past six months [40]. Dichotomized variables represented whether a substance or medication was reported as one of a participant's most commonly used; each participant could therefore be categorized as a user of up to four substances. Anxiety or depression warranting clinical attention were indicated by scores above 1.0 on the HSCL-25's 10-item anxiety subscale and the 15-item depression subscale, respectively, each measured on a $0-4$ scale [41]. No participant was missing more than one item per subscale, and missing items were excluded in the calculation of the mean subscales.

Those who reported at least one chronic somatic disease, e.g. coronary heart disease, diabetes, or hepatitis C, were analysed as a "chronic disease" group. Participants also self-reported smoking, using smokeless tobacco, exercising regularly in the past six months (using their own definition of exercise) and dis/satisfaction with their current weight; these variables were chosen based on associations found at baseline with low QoL [42]. Participants were categorized based on their entry at the beginning of the study into eithert OMT or medication-free residential treatment.

Finally, participants answered a social network question from the EuropASI, "with whom do you spend most of your free time?" Answers included "alone", indicating social isolation, "with substance-using family/friends", or "with substance-free family/friends". This question was used as a three-category variable as well as dichotomized into a social isolation variable. Living situation was also collected in another variable and was reported as "alone", "with partner/family", or "with friends/others".

\section{Analysis}

The scaling qualities of the WHOQOL-BREF's four domains are described, including internal validity and item-total statistics. The responsiveness of certain items in the WHOQOL-BREF to similar clinical/objective variables describing the sample are reported using Mann-Whitney U tests. To determine which of the variables collected were associated with each domain of quality of life and to what extent they could explain the domains' variances, a general linear model was created for each domain. Domain scores were dependent variables, and independent variables were those demonstrating significant bivariate associations to each domain, tested using the Kruskal-Wallis test. HSCL-25 anxiety and depression subscores were significantly associated with each domain, and in order not to lose information in the analysis by dichotomizing them using the 1.0 cut-off score, the scores themselves were added as covariates in each adjusted model. Age was correlated with the physical health domain, and was added as a covariate only in this domain's adjusted model. Two-way interactions were requested between all independent variables, which were included stepwise at $p<0.05$. Model fit was reported by adjusted $R^{2}$. All statistics were conducted in SPSS version 22 .

\section{Results \\ Participants' characteristics}

Table 1 displays the demographic, substance, health, and social variables of the 107 participants included in this analysis.

$34 \%$ of participants were women, and the mean age was $34.3(S D=9.6)$. The majority were single, had a primary education or lower, and were unemployed. Sixty-five participants had entered into OMT (60.7\%) and 42 had begun residential treatment (39.3\%) at study inclusion. When interviewed again at follow-up, 19.9\% were no longer in treatment, $22.9 \%$ were in residential treatment, $43.8 \%$ were in OMT, and the $14.3 \%$ were receiving non-OMT outpatient treatment. Half $(49.0 \%)$ reported polysubstance use in the past 6 months, while $19.6 \%$ reported only one substance, and $34.6 \%$ reported none (excluding prescribed medication users). Participants reported their four most frequently used substances in this time period from an exhaustive list, and cannabis was the most common (reported by $42.1 \%$ ), followed by amphetamines (29.9\%), alcohol (25.2\%), unprescribed benzodiazepines (20.6\%), and heroin (17.8\%). One fourth $(25.5 \%)$ had injected within the past 4 weeks.

Two-thirds reported at least one chronic somatic disease $(66.4 \%)$, while nearly $60 \%$ reported symptoms of clinical anxiety or clinical depression, and half had received professional psychiatric services in the past year. Half were dissatisfied with their weight. While most smoked cigarettes (84.1\%) and one third used smokeless tobacco (34.3\%), exercising was also common (64.5\%). Finally, $18.7 \%$ reported being socially isolated, while half $(55.5 \%)$ said their social network was abstinent, and $26.2 \%$ had a substance-using network. Most 
Table 1 Characteristics of 107 participants followed up with in the NorComt study

\begin{tabular}{ll}
\hline & $\mathrm{n}(\%)$ \\
\hline Demographics & \\
Age (mean, SD) & $35.3(9.6)$ \\
Women & $36(33.6)$ \\
Single & $78(77.2)$ \\
Primary education or less & $61(57.0)$ \\
Unemployed & $76(71.0)$ \\
Substance-related variables & \\
No substance use & $27(34.6)$ \\
Polysubstance user & $49(49.0)$ \\
Substances & \\
Cannabis & $45(42.1)$ \\
Amphetamines & $32(29.9)$ \\
Alcohol & $27(25.2)$ \\
$\quad$ Unprescribed benzodiazepines & $22(20.6)$ \\
Heroin/opium & $19(17.8)$ \\
Ecstasy, LSD & $3(2.8)$ \\
Cocaine & $2(1.9)$ \\
Other central stimulants or addictive substances & $1(0.9)$ \\
Crack, solvents, or denatured alcohol & 0 \\
Injected within past four weeks & $25(25.5)$ \\
Current SUD treatment & \\
OMT & $46(43.8)$ \\
Residential & $24(22.9)$ \\
Outpatient (without OMT) & $15(14.3)$ \\
None & $20(19.9)$ \\
& \\
\hline
\end{tabular}

Health variables

Chronic somatic disease

Clinical anxiety symptoms

Clinical depression symptoms

Received psychiatric services, past year

Exercise

Dissatisfied with weight

Smoke cigarettes

Use smokeless tobacco

Social variables

$$
\begin{aligned}
& \text { Social network } \\
& \text { Abstinent } \\
& \text { Substance-using } \\
& \text { No network } \\
& \text { Living situation } \\
& \text { With partner/family } \\
& \text { Friends or others } \\
& \text { Alone }
\end{aligned}
$$

participants lived alone $(57.0 \%)$, one third with a partner or family $(30.8 \%)$, and $12.1 \%$ with friends or others.

\section{WHOQOL-BREF item responses and responsiveness}

There were few skipped or missing data overall in the WHOQOL-BREF. 99.8\% of the items were answered; only five participants $(4.6 \%)$ had any missing data, and each participant skipped no more than one item. The item "how satisfied are you with your sex life?" was missing for four of these participants, all of whom reported being single. The fifth participant did not answer the item "how satisfied are you with the support you get from your friends?", although did not report being isolated.

No ceiling or floor effects were identified for any of the items. The most skewed item was in the physical health QoL domain, "to what extent do you feel that physical pain prevents you from doing what you need to do?" $51 \%$ of respondents selected the most impaired response, "an extreme amount", and in decreasing proportions towards the least impaired response, "not at all", selected by only $4 \%$. Another item in this domain, "How much do you need any medical treatment to function in your daily life?" had a U-shape, with nearly equal proportions answering the two extremes: 28\% "not at all" and 26\% "an extreme amount".

The responsiveness of several items in the WHOQOLBREF to convergent objective variables was promising. The item, "How much do you need any medical treatment to function in your daily life?" successfully distinguished between those currently in opioid maintenance treatment and those not, $p<0.001$. Similarly, "How often do you have negative feelings such as blue mood, despair, anxiety, depression?" distinguished between those with symptoms of clinical depression $(p<0.001)$, clinical anxiety $(p<0.001)$, and who had received psychiatric services in the past year $(p=0.014)$. Unemployment status was distinguished by responses to the item, "How satisfied are you with your capacity for work?" $(p<0.001)$. "Are you able to accept your bodily appearance?" distinguished between those were satisfied with their weight versus dissatisfied $(p=0.017)$.

Finally, two items are included in the WHOQOLBREF which do not contribute to domain scores. An item asking for an overall rating of QoL was answered "very poor" by $0.9 \%$, "poor" by $13.1 \%$, "neither good nor poor" by $34.6 \%$, "good" by $36.4 \%$, and "very good" by $15.0 \%$. In response to "how satisfied are you with your health?", $2.8 \%$ answered "very dissatisfied", 18.7\% "dissatisfied", 31.8\% "neither satisfied nor dissatisfied", "37.4\%" "satisfied", and 9.3\% "very satisfied".

\section{Scaling qualities}

Table 2 displays scaling qualities of the WHOQOLBREF. The physical health domain had the lowest mean 
Table 2 Scaling qualities of the WHOQOL-BREF domains

\begin{tabular}{lllll}
\hline & $\begin{array}{l}\text { Physical health QoL } \\
(N=107)\end{array}$ & $\begin{array}{l}\text { Psychological health QoL } \\
(N=107)\end{array}$ & $\begin{array}{l}\text { Social relation-ships QoL } \\
(N=102)\end{array}$ & $\begin{array}{l}\text { Environment QoL } \\
(N=107)\end{array}$ \\
\hline Mean (SD) & $44.87(16.98)$ & $54.60(17.11)$ & $62.34(18.50)$ & $57.29(16.82)$ \\
Median (IQR) & $46.43(17.83-17.03)$ & $54.41(33.57-75.25)$ & $58.33(33.33-83.33)$ & $56.25(33.60-78.90)$ \\
Range & $3.6-82.1$ & $16.67-100$ & $8.33-100$ & $25-96.88$ \\
Cl & $41.59-48.10$ & $51.32-57.87$ & $58.70-65.97$ & $54.06-60.51$ \\
Kurtosis (SE) & $-0.27(0.46)$ & $0.26(0.46)$ & $0.14(0.47)$ & $-0.73(0.46)$ \\
Skewness (SE) & $-0.29(0.23)$ & $0.25(0.23)$ & $-0.19(0.24)$ & $0.16(0.23)$ \\
Significant test of normality & $p=0.037$ & $p=0.004$ & $p<0.001$ & $p=0.024$ \\
Cronbach's alpha & 0.763 & 0.792 & 0.541 & 0.762 \\
\hline
\end{tabular}

${ }^{\mathrm{a}}$ One-Sample Kolmogorov-Smirnov Tests. QoL quality of life, IQR interquartile range, SE standard error

Physical health, psychological health, and environment QoL domains of the WHOQOL-BREF exhibited satisfactory scaling qualities among a substance use disorder treatment population

(45) and median (46) as well as the smallest range (4-82). The social relationships domain was scored the highest (mean: 62, median: 58), a larger range (8-100), and the most normal and symmetric distribution among the domains. Psychological health and environment domains had similar means (55 and 57, respectively).

Cronbach's alpha was acceptable for the physical health QoL (0.763), psychological health QoL (0.792), and environment QoL (0.762), but lower for social relationships QoL, (0.541). Reliability analysis suggested all items were worthy of retention. All items had acceptable corrected item-total correlation, greater than 0.3 and up to 0.7 , with their respective domain scores. The four domain scores correlated moderately to strongly with one another, with correlation coefficients, displayed in Table 3.

\section{Correlates of impaired QoL}

\section{Physical health QoL domain}

The following groups differed in their physical health QoL scores, on a $0-100$ scale $(p<0.05)$ : participants who were unemployed (40.5), smoked (43.4), physically inactive (36.1), and socially isolated (32.1) reported lower scores than those who were employed (55.6), nonsmokers (52.7), physically active (49.7), and were not socially isolated (47.1), respectively. In addition, participants who were dissatisfied with their weight reported worse physical health QoL (39.9) than those who evaluated their weight as appropriate (49.7). Lower scores

Table 3 WHOQOL-BREF domain correlations

\begin{tabular}{llll}
\hline & Physical health & $\begin{array}{l}\text { Psychological } \\
\text { health }\end{array}$ & $\begin{array}{l}\text { Social } \\
\text { relationships }\end{array}$ \\
\hline Psychological health & $.533^{\mathrm{a}}$ & & \\
Social relationships & $.506^{\mathrm{a}}$ & $.553^{\mathrm{a}}$ & \\
Environment & $.553^{\mathrm{a}}$ & $.503^{\mathrm{a}}$ & $.472^{\mathrm{a}}$ \\
\hline
\end{tabular}

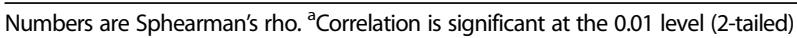
The four domains of the WHOQOL-BREF correlated moderately to strongly with one another were also reported by those who used benzodiazepines (40.3) than those who did not (47.7), and by participants in the OMT cohort (42.9) instead of residential treatment (57.1).

In an adjusted model containing these variables (Table 2), depression and unemployment had significant main effects on physical health QoL. An increase in the HSCL-25 depression score and unemployment reduced this domain by 8.0 points, and unemployment reduced this domain score by 26.9 points. Social isolation did not have a significant main effect, but several interaction effects including social isolation did. The interaction between social isolation and smoking lowered one's score by 32.4 points. The interaction between social isolation and entering the study in residential treatment as opposed to OMT lowered this score by 20.2 points, and the interaction between social isolation and weight dissatisfaction lowered this score by 16.6 points. This model accounted for $59.0 \%$ of the variance.

\section{Psychological health QoL domain}

Bivariate analyses showed that participants who were partnered or married instead of single reported higher psychological health QoL (60.4 compared to 52.1), as well as those who lived with a partner or family (60.3) instead of alone (52.2) or with friends or others (51.5).

In an adjusted model with these variables (Table 4), living situation has no main effect or interaction effect, but there were significant main effects of depression and being single. An increase in the HSCL-25 depression score corresponds to a decrease in 11.9 points in psychological health QoL, and being single instead of partnered/married reduces this score by 9.4 points. This model explains $52.4 \%$ of the variance.

\section{Social relationships QoL domain}

Those who reported social isolation reported lower social relationships QoL (54.8) than those not isolated (64.1). 
Table 4 Adjusted models explaining variance in WHOQOL-BREF domains

\begin{tabular}{|c|c|c|c|}
\hline $\begin{array}{l}\text { Variables with significant main } \\
\text { effects or interaction effects }\end{array}$ & B & $p$ & $R^{2}$ \\
\hline Physical health QoL ${ }^{a}$ & & & 0.590 \\
\hline Depression score & -8.0 & 0.001 & \\
\hline Unemployment & -26.9 & 0.048 & \\
\hline Social isolation * smoking & -32.4 & 0.040 & \\
\hline Social isolation * residential treatment & -20.2 & 0.034 & \\
\hline Social isolation * weight dissatisfaction & -16.6 & 0.026 & \\
\hline Psychological health QoL ${ }^{b}$ & & & 0.524 \\
\hline Depression score & -11.9 & $<0.001$ & \\
\hline Single & -9.4 & 0.037 & \\
\hline Social relationships QoL ${ }^{c}$ & & & 0.271 \\
\hline Depression score & -14.3 & 0.001 & \\
\hline Environment QoL ${ }^{\mathrm{d}}$ & & & 0.386 \\
\hline Depression score & -7.2 & 0.043 & \\
\hline Social isolation * no cannabis & -27.0 & 0.036 & \\
\hline Social isolation * exercise & -19.6 & 0.004 & \\
\hline Exercise $*$ no amphetamines & +26.8 & 0.003 & \\
\hline
\end{tabular}

QoL Quality of life

Not significant in adjusted models, after stepwise inclusion: aunemployment, smoking, physical inactivity, weight dissatisfaction, benzodiazepine use, opioid maintenance treatment cohort. ${ }^{b}$ partner status, living situation. ${ }^{\mathrm{C}}$ social isolation. ${ }^{d}$ employment, psychiatric services received, social isolation, chronic disease, physical activity, polysubstance use, cannabis use, amphetamine use Depression and social factors, rather than the direct effects of substance use or severity, explained most of the variance of the physical health and psychological health QoL domains of the WHOQOL-BREF

This was the only variable with a significant correlation to social relationships QoL.

In the adjusted model (Table 4), only depression had a significant main effect on domain scores. An increase in depression scores resulted in a 14-point decrease in social relationships QoL domain. There was also a trend for a negative effect of social isolation. This model explains only $27.1 \%$ of the combined variance of QoL scores.

\section{Environment QoL domain}

The environment QoL domain had the most variables with significant bivariate associations: lower environment QoL was reported by those who were unemployed (53.8) compared to employed (65.7), had not received psychiatric services in the past year (54.0) compared to those who had (60.4), were socially isolated (46.2) instead of having a network (59.8), had a chronic disease (54.7) instead of none (62.4), were physically inactive (50.0) instead of active (60.6), were polysubstance users (50.2) compared to single-substance users (60.8) or substance-free/prescribed-only substance users (64.6), consumed cannabis (51.8) instead of no cannabis (61.2), and consumed amphetamines (46.8) instead of no amphetamines (61.8).
In the adjusted model (Table 4), an increase in the HSCL-25 depression score reduced the environment QoL domain by 7.2 points. There was also an interaction effect of exercising and not consuming amphetamines, improving environment QoL by 26.8 points. Social isolation did not have a significant main effect, but had a negative interaction effect with several other variables. The interaction effect of being socially isolated and not consuming cannabis reduced this domain score by 27.0 points, while being socially isolated and exercising reduced this domains core by 19.6 points. There was also a trend for the interaction effect of social isolation and having a chronic disease to decrease environment QoL. This model accounted for $38.6 \%$ of the variance of environment QoL.

\section{Discussion}

In the first such analysis of the WHOQOL-BREF in Norway, lacking regular (reported) social contact had a strong negative effect on numerous dimensions of QoL of 107 participants in a substance use disorder treatment study. Along with depression, social factors were more important than direct effects of substance use or of severity indicators. The WHOQOL-BREF exhibited satisfactory scaling qualities and user acceptability and is therefore overall considered a useful tool among this population, but its social relationships domain needs further investigation. We recommend that the social lives of people with SUD receive more attention in future QoL instrument development and in treatment.

The poor QoL reported by this sample is in line with a larger body of research on SUD populations [7, 43, 44]. Of novelty in this analysis is our exploration of social contributors to QoL. This sample reported concerningly low levels of social contact and engagement, with $18 \%$ reporting being isolated, $57 \%$ living alone, $77 \%$ without a partner, and $71 \%$ disconnected from both the labour market and educational system. A qualitative study of OMT patients in Belgium reported a similar paucity of social contact, and patients linked their lack of daily activities to feeling alone and without emotional support [45]. The effects of such social disengagement in our sample extended beyond the social relationships QoL domain, and low social contact had negative interaction effects in every other domain. Social isolation appears so detrimental to well-being that it overrode the positive effect of exercising in the environment QoL domain. The environment domain may also indicate social inclusion, as it measures aspects such as access to social care and participation in leisure activities. This sample reported slightly lower environment QoL than social relationships QoL.

Other negative health-related variables such as smoking and being dissatisfied with one's weight, in tandem 
with social isolation, reduced the physical health QoL domain. Smoking and weight dissatisfaction are common among people in SUD treatment [46-48], which is particularly concerning given evidence that smoking cessation is associated with higher rates of long-term abstinence from other substances [49], yet is not standardly integrated into treatment programs [50]. More than half of the sample reported symptoms of clinical depression, which was a component of poorer QoL in every domain, in alignment with extensive international [7, 8, 51], Scandinavian [46], and Norwegian research [52] reporting mental health as a factor in QoL among SUD populations. We found no correlation between active substance use or treatment variables to the physical health, psychological health or social relationships domains of QoL, contributing to existing mixed evidence of these relationships among people with SUD [6-9, 53, 54]. The environment QoL domain was most responsive to substance use variables in bivariate analyses and to a lesser extent in the adjusted model, and the validity of this domain may be higher for people in active substance-using phases than for those in other populations.

Many of the components of poor QoL seen in this analysis can be addressed in treatment. When depression is addressed, symptoms can improve significantly and their corresponding treatment barriers alleviated [55]. Similarly, lifestyle interventions among SUD populations have been successfully implemented to reduce smoking and encourage other health-promoting behaviours such as healthy eating, sleep hygiene, and exercise [46, 5658]. Social contact itself can support healthy behavioural change, as reported in a recent qualitative analysis of alcohol treatment patients who dropped out of an exercise intervention [59]. These results suggest that in addition to mental health and exercise, specific interventions aiming at improving social contact should also be a focus during treatment.

Social isolation was operationalized through answering the question, "with whom do you spend most of your free time?" with "mostly alone". Patients may have responded differently had they been asked directly if they were isolated. Being mostly alone could be a temporary situation resulting from a recent change in social situation, such as loss of a job or a partner, or following relocation. It could also be an intentional technique utilized by those who would otherwise only have substance-using people around them, as described in previous qualitative studies [60-62] At the same time, people in recovery have also reported loneliness as an instigator for relapse [63, 64]. As Mau et al. [65] have recently discussed, while the agency of people with SUD in negotiating their own loneliness and isolation should be acknowledged, "loneliness should not be clinically accepted as a requirement or side-effect of recovery in the long-term" (p.12).

The WHOQOL-BREF performed well as a whole, with the exception of the social relationships domain. Expected social variables such as isolation or relationship status did not explain observed variance in this domain, and in fact, our model did not adequately explain variance. Most likely, the three questions that comprise this domain - how satisfied are you with your personal relationships, support from friends, and sex life? - are simply too few, and should be supplemented with items from the larger WHOQOL-100 instrument. The negative interaction effects of low social contact on almost all domains, along with the low internal consistency of the social relationships domain, underscore the need for QoL tools to capture the social lives of people with SUD and likely other marginalised groups, but the importance of social factors is belied by the size of this domain in the WHOQOL-BREF. This may require the development of a new generic QoL tool with a greater focus on social QoL.

The heterogeneity of this sample - including users of different substances and having entered different treatment modalities - is a strength of this study, as the SUD population itself is diverse. Nevertheless, this sample was relatively small, prohibiting stratified analyses such as by gender. No gender differences in QoL were found in previous analyses from the larger study from which this sample was drawn $[42,66]$, but there may be a gender aspect to social networks and contact, and it is worth exploring this further. Another limitation is that the larger study did not utilize a random sampling design, limiting generalizability of the study's and of this sample's characteristics to the Norwegian patient population. While this analysis is therefore less capable of providing specific prevalence rates, the correlations found between QoL, exercise, and social contact seem stable, as they were also found in analysis of the larger study at baseline [42] and follow-up [66].

\section{Conclusion}

The WHOQOL-BREF is a short, valid measure of QoL among a SUD treatment population and exhibited acceptable scaling properties and item discrimination. More attention to the social relationships domain is required, however, and better information may be collected through additional questions/developments. The negative effect of low social contact with other variables was seen in every domain of QoL, and treatment providers should monitor the contact patients report when they enter treatment, during treatment, and at discharge. Addressing the quality and functionality of the social contact and support that patients have may be an important part of intake and future treatment processes, in 
order to best support patients' engagement with people supportive to their recovery. These findings may also be relevant for other patient groups with high rates of isolation, and a focus on increasing social contact may be an important element to add to the health care of marginalized populations.

\section{Abbreviations \\ NorComt: Norwegian Cohort of Patients in Opioid Maintenance Treatment and other Drug Treatment study; QoL: Quality of life; SUD: Substance use disorder; WHOQOL-BREF: World Health Organization's Quality of Life Brief assessment}

\section{Acknowledgements}

The authors wish to thank NorComt participants for their willingness to contribute to this sub-study, as well as Ingeborg Skjærvø for her contributions in data collection and cleaning.

\section{Funding}

This study was funded by the Norwegian Centre for Addiction Research.

\section{Availability of data and materials}

Data is not yet available due to ongoing analyses.

\section{Authors' contributions}

AEM collected participant data, performed the statistical analysis, and drafted the paper. SS participated in the statistical analysis, discussion of the paper, and writing up. TC was the project manager for the study and participated in the statistical analysis, discussion of the paper, and writing up. All authors read and approved the final manuscript.

\section{Authors' information}

Dr. Muller specializes in assessing the quality of life and other patient-reported outcomes of marginalized populations. Dr. Skurtveit is a pharmacoepidemiologist and works with countries across Europe to identify emerging trends of problematic opioid use. Dr. Clausen leads the Norwegian Centre for Addiction Research and advises the EMCDDA and WHO on issues of substance use and healthy ageing.

\section{Ethics approval and consent to participate}

The Norwegian Regional Ethics Committee approved the study (ref: 2012/ 1131/REK). Written informed consent was obtained from all individual participants prior to inclusion into the study.

\section{Consent for publication}

Not applicable.

\section{Competing interests}

The authors declare that they have no competing interests.

\section{Publisher's Note}

Springer Nature remains neutral with regard to jurisdictional claims in published maps and institutional affiliations.

\section{Author details \\ ${ }^{1}$ Norwegian Centre for Addiction Research, Institute of Clinical Medicine, University of Oslo, Pb 1039 Blindern, 0315 Oslo, Norway. ²Division of Health Services, Norwegian Institute of Public Health, Pb 4044 Nydalen, 0403 Oslo, Norway. ${ }^{3}$ Department of Mental Disorders, Norwegian Institute of Public Heath, Pb 4044 Nydalen, 0403 Oslo, Norway.}

Received: 15 June 2018 Accepted: 22 February 2019

Published online: 04 March 2019

\section{References}

1. Laudet $A B$. The case for considering quality of life in addiction research and clinical practice. Addiction science \& clinical practice. 2011;6(1):44-55.

2. Monroe AK, Jabour SM, Peña S, Keruly JC, Moore RD, Chander G, Riekert KA A qualitative study examining the benefits and challenges of incorporating patient-reported outcome substance use and mental health questionnaires into clinical practice to improve outcomes on the HIV care continuum. BMC Health Serv Res. 2018;18(1):1-10.

3. Best D, Savic M, Beckwith M, Honor S, Karpusheff J, Lubman DI. The role of abstinence and activity in the quality of life of drug users engaged in treatment. J Subst Abus Treat. 2013;45(3):273-9.

4. Laudet $A B$, Becker JB, White WL. Don't Wanna go through that madness no more: quality of life satisfaction as predictor of sustained remission from illicit drug misuse. Subst Use Misuse. 2009;44(2):227-52.

5. Laudet $A B$, Stanick V. Predictors of motivation for abstinence at the end of outpatient substance abuse treatment. J Subst Abus Treat. 2010;38(4):317-27.

6. Rudolf H, Watts J. Quality of life in substance abuse and dependency. International Review of Psychiatry. 2002;14(3):190-7.

7. Colpaert K, De Maeyer J, Broekaert E, Vanderplasschen W. Impact of addiction severity and psychiatric comorbidity on the quality of life of alcohol-, drug- and dual-dependent persons in residential treatment. Eur Addict Res. 2013;19(4):173-83.

8. De Maeyer J, Vanderplasschen W, Broekaert E. Quality of life among opiatedependent individuals: a review of the literature. Int J Drug Policy. 2010;21:16.

9. Dawson DA, Li TK, Chou SP, Grant BF. Transitions in and out of alcohol use disorders: their associations with conditional changes in quality of life over a 3-year follow-up interval. Alcohol Alcohol. 2009;44(1):84-92.

10. Weiss L, Gass J, Egan JE, Ompad DC, Trezza C, Vlahov D. Understanding prolonged cessation from heroin use: findings from a community-based sample. J Psychoactive Drugs. 2014;46(2):123-32.

11. De Maeyer J, Vanderplasschen W, Broekaert E. Exploratory study on drug Users' perspectives on quality of life: more than health-related quality of life? Soc Indic Res. 2009;90(1):107-26.

12. De Maeyer J, Vanderplasschen W, Camfield L, Vanheule S, Sabbe B, Broekaert E. A good quality of life under the influence of methadone: a qualitative study among opiate-dependent individuals. Int J Nurs Stud. 2011;48(10):1244-57.

13. Strada L, Franke GH, Schulte B, Reimer J, Verthein U. Development of OSTQOL: a measure of quality of life for patients in opioid substitution treatment. Eur Addict Res. 2017;23(5):238-48

14. Hser Y-I, Anglin MD, Booth MW. Sex differences in addict careers. 3. Addiction. Am. J. Drug Alcohol Abuse. 2009;13(3):231-51.

15. Y-I H, Anglin MD, McGlothlin W. Sex differences in addict careers. 1. Initiation of use. Am. J. Drug Alcohol Abuse. 2009;13(1-2):33-57.

16. Bohnert AS, Bradshaw CP, Latkin CA. A social network perspective on heroin and cocaine use among adults: evidence of bidirectional influences. Addiction. 2009;104(7):1210-8.

17. Pinquart $\mathrm{M}$, Sorensen S. Influences of socioeconomic status, social network, and competence on subjective well-being in later life: a meta-analysis. Psychol Aging. 2000;15(2):187-224.

18. Chronister J, Chou CC, Liao HY. The role of stigma coping and social support in mediating the effect of societal stigma on internalized stigma, mental health recovery, and quality of LIFE among people with serious mental illness. J. Community Psychol. 2013;41(5):582-600.

19. Hansson L, Bjorkman T. Are factors associated with subjective quality of life in people with severe mental illness consistent over time?--a 6-year followup study. Qual Life Res. 2007;16(1):9-16.

20. Björkman T, Hansson L. Predictors of improvement in quality of life of long-term mentally ill individuals receiving case management. European Psychiatry. 2002; 17(1):33-40.

21. Fleury M-J, Grenier G, Bamvita J-M, Tremblay J, Schmitz N, Caron J. Predictors of quality of life in a longitudinal study of users with severe mental disorders. Health Qual Life Outcomes. 2013;11:92.

22. Skevington S, Lotfy M, O'Connell K. The World Health Organization's WHOQOL-BREF quality of life assessment: Psychometric properties and results of the international field trial. A Report from the WHOQOL Group. Qual Life Res. 2004;13(2):11.

23. Mathiesen E, Nome S, Eisemann M, Richter J. Drinking patterns, psychological distress and quality of life in a Norwegian general population-based sample. Qual Life Res. 2012;21(9):1527-36.

24. Hanestad BR, Rustøen T, Knudsen $\varnothing \mathrm{Jr}$, Lerdal A, Wahl AK. Psychometric properties of the WHOQOL-BREF questionnaire for the Norwegian general population. J Nurs Meas. 2004;12(2):147-59.

25. Noerholm V, Groenvold M, Watt T, Bjorner JB, Rasmussen NA, Bech P. Quality of life in the Danish general population--normative data and validity of WHOQOL-BREF using Rasch and item response theory models. Qual Life Res. 2004;13(2):531-40. 
26. Fu T, Tuan Y-C, Yen M-Y, Wu W-H, Huang C-W, Chen W-T, Li C-S, Lee T-S, Psychometric properties of the world health organization quality of life assessment brief in methadone patients: a validation study in northern Taiwan. Harm Reduct J. 2013;10:37.

27. Chang KC, Wang JD, Tang HP, Cheng CM, Lin CY. Psychometric evaluation, using Rasch analysis, of the WHOQOL-BREF in heroin-dependent people undergoing methadone maintenance treatment: further item validation. Health Qual Life Outcomes. 2014;12:148.

28. Barros da Silva Lima AF, Fleck M, Pechansky F, de Boni R, Sukop P. Psychometric properties of the World Health Organization quality of life instrument (WHOQoL-BREF) in alcoholic males: a pilot study. Qual Life Res. 2005;14(2):473-8.

29. Garcia-Rea EA, LePage JP. Reliability and validity of the World Health Organization quality of life: brief version (WHOQOL-BREF) in a homeless substance dependent veteran population. Soc Indic Res. 2010;99(2):333-40.

30. Kirouac M, Stein ER, Pearson MR, Witkiewitz K. Viability of the World Health Organization quality of life measure to assess changes in quality of life following treatment for alcohol use disorder. Qual Life Res. 2017;26(11): 2987-97.

31. Strada L, Vanderplasschen W, Buchholz A, Schulte B, Muller AE, Verthein U, Reimer J. Measuring quality of life in opioid-dependent people: a systematic review of assessment instruments. Qual Life Res. 2017;26(12):3187-200.

32. Hubley AM, Palepu A. Injection drug user quality of life scale (IDUQOL): findings from a content validation study. Health Qual Life Outcomes. 2007;5:46.

33. Bray JW, Aden B, Eggman AA, Hellerstein L, Wittenberg E, Nosyk B, Stribling JC, Schackman BR. Quality of life as an outcome of opioid use disorder treatment: a systematic review. J Subst Abus Treat. 2017;76:88-93.

34. Muller A, Clausen T. Group exercise to improve quality of life among substance use disorder patients. Scand J Public Health. 2015;43(2):6.

35. Skjærvø I, Skurtveit S, Clausen T, Bukten A. Substance use pattern, self-control and social network are associated with crime in a substance-using population. Drug and Alcohol Review. 2016;36(2):245-52.

36. Skjærvø I, Clausen T, Skurtveit S, Abel EKF, Bukten A. Similarities and differences in victimization risk factors for nonoffending and offending substance users. Vict Offenders. 2018;13(4):526-41.

37. Muller A, Skurtveit S, Clausen T. Validating the generic quality of life tool "QOL10" in a substance use disorder treatment cohort exposes a unique social construct. BMC Med Res Methodol. 2016;16(1):1-8.

38. Helsedirektoratet: Veileder for rapportering i tverrfaglig spesialisert rusbehandling (TSB): Rapportering til Norsk pasientregister [Guidance for registration in specialist treatment services for substance use disorders: reporting to the National Patient Registry]. In. Edited by Health NDo; 2012.

39. The WHOQOL Group: WHOQOL-BREF: Introduction, Administration, Scoring, and Generic Version of the Assessment. In.: World Health Organization; 1996: 18.

40. Lauritzen G, Ravndal E. Introduction of the EuropASI in Norway: clinical and research experiences from a cost-effectiveness study. J Subst Abus. 2004; 9(3-4):5.

41. Ravndal E, Lauritzen G. En prospektiv studie av stoffmisbrukere i behandling i Norge [A prospective study of substance abusers in treatment in Norway]. NORDISK ALKOHOL- \& NARKOTIKATIDSKRIFT [Nordic Journal of Alcohol and Narcotics]. 2004;21(6):17.

42. Muller A, Skurtveit S, Clausen T. Many correlates of poor quality of life among substance users entering treatment are not addiction-specific. Health Qual Life Outcomes. 2016:14(1):1-10.

43. Fischer JA, Conrad S, Clavarino AM, Kemp R, Najman JM. Quality of life of people who inject drugs: characteristics and comparisons with other population samples. Qual Life Res. 2013;22(8):2113-21.

44. Foster JH, Powell JE, Marshall EJ, Peters TJ. Quality of life in alcohol-dependent subjects - a review. Qual Life Res. 1999;8(3):255-61.

45. Vanderplasschen W, Naert J, Vander Laenen F, De Maeyer J. Treatment satisfaction and quality of support in outpatient substitution treatment: opiate users' experiences and perspectives. Drugs Educ Prev Po. 2014; 22(3):272-80.

46. Juel A, Kristiansen CB, Madsen NJ, Munk-Jorgensen P, Hjorth P. Interventions to improve lifestyle and quality-of-life in patients with concurrent mental illness and substance use. Nord J Psychiatry. 2016;71(3):1-8.

47. Guydish J, Passalacqua E, Pagano A, Martinez C, Le T, Chun J, Tajima B, Docto L, Garina D, Delucchi K. An international systematic review of smoking prevalence in addiction treatment. Addiction. 2016:111(2):220-30.
48. Cowan J, Devine C. Food, eating, and weight concerns of men in recovery from substance addiction. Appetite. 2008;50(1):33-42.

49. Tsoh JY, Chi FW, Mertens JR, Weisner CM. Stopping smoking during first year of substance use treatment predicted 9-year alcohol and drug treatment outcomes. Drug Alcohol Depend. 2011;114(2):110-8.

50. Knudsen HK, Muilenburg J, Eby LT. Sustainment of smoking cessation programs in substance use disorder treatment organizations. Nicotine Tob Res. 2013;15(6):1060-8.

51. Bizzarri J, Rucci P, Vallotta A, Girelli M, Scandolari A, Zerbetto E, Sbrana A, lagher C, Dellantonio E. Dual diagnosis and quality of life in patients in treatment for opioid dependence. Subst Use Misuse. 2005:40(12):1765-76.

52. Vederhus J-K, Pripp AH, Clausen T. Quality of life in patients with substance use disorders admitted to detoxification compared with those admitted to hospitals for medical disorders: follow-up results. Substance Abuse: Research and Treatment. 2016:10:31-7.

53. De Maeyer J, van Nieuwenhuizen C, Bongers IL, Broekaert E, Vanderplasschen W. Profiles of quality of life in opiate-dependent individuals after starting methadone treatment: a latent class analysis. Int I Drug Policy. 2013;24(4):342-50.

54. Hagen E, Erga AH, Hagen KP, Nesvag SM, McKay JR, Lundervold AJ, Walderhaug E. One-year sobriety improves satisfaction with life, executive functions and psychological distress among patients with polysubstance use disorder. J Subst Abus Treat. 2017:76:81-7.

55. SAMSHA. Managing depressive symptoms in substance abuse clients during early recovery. In: Treatment Improvement Protocol (TIP) Series. Rockville MD: Center for Substance Abuse Treatment; 2008.

56. Apollonio D, Philipps R, Bero L. Interventions for tobacco use cessation in people in treatment for or recovery from substance use disorders. Cochrane Database Syst Rev. 2016;11:CD010274.

57. Roessler KK, Bilberg R, Sogaard Nielsen A, Jensen K, Ekstrom CT, Sari S. Exercise as adjunctive treatment for alcohol use disorder: a randomized controlled trial. PLoS One. 2017;12(10):e0186076.

58. Cowan J, Devine C. Diet and body composition outcomes of an environmental and educational intervention among men in treatment for substance addiction. J Nutr Educ Behav. 2013;45(2):154-8.

59. Sari S, Muller AE, Roessler KK. Exercising alcohol patients don't lack motivation but struggle with structures, emotions and social context - a qualitative dropout study. BMC Fam Pract. 2017;18(1):1-7.

60. Brooks AT, Magaña Lòpez M, Ranucci A, Krumlauf M, Wallen GR. A qualitative exploration of social support during treatment for severe alcohol use disorder and recovery. Addict Behav Rep. 2017;6:76-82.

61. Brown S, Tracy EM, Jun M, Park H, Min MO. Personal network recovery enablers and relapse risks for women with substance dependence. Qual Health Res. 2015;25(3):371-85.

62. Tracy EM, Munson MR, Peterson LT, Floersch JE. Social support: a mixed blessing for women in substance abuse treatment. I Soc Work Pract Addict. 2010:10(3):257-82.

63. Laudet AB, Magura S, Vogel HS, Knight EL. Perceived reasons for substance misuse among persons with a psychiatric disorder. Am. J. Orthopsychiatry. 2004;74(3):365-75.

64. Trombello JM, Carmody T, Greer TL, Walker R, Rethorst C, Trivedi M. Psychosocial relationship status and quality as predictors of intervention adherence and substance use outcomes: results from the STRIDE (CTN0037) study. Psychiatry Res. 2017;254:332-9.

65. Mau M, Muller AE, Roessler KK. Alcohol relapse and near-relapse experiences show that relapse models need to be updated. Alcohol Treat Q. 2018:1-17.

66. Muller A, Skurtveit S, Clausen T. Building abstinent networks is an important resource in improving quality of life. Drug Alcohol Depend. 2017; 180(Supplement C):431-8.

\section{Ready to submit your research? Choose BMC and benefit from}

- fast, convenient online submission

- thorough peer review by experienced researchers in your field

- rapid publication on acceptance

- support for research data, including large and complex data types

- gold Open Access which fosters wider collaboration and increased citations

- maximum visibility for your research: over $100 \mathrm{M}$ website views per year

At $\mathrm{BMC}$, research is always in progress.

Learn more biomedcentral.com/submissions 